\title{
LMNA Mutations Induce a Non-Inflammatory Fibrosis and a Brown Fat-Like Dystrophy of Enlarged Cervical Adipose Tissue
}

\author{
Véronique Béréziat, ${ }^{\star \dagger \ddagger}$ Pascale Cervera, ${ }^{\star \dagger \ddagger \S}$ \\ Caroline Le Dour, ${ }^{* \dagger \ddagger}$ Marie-Christine Verpont, ${ }^{\ddagger}$ \\ Sylvie Dumont, ${ }^{\star \S}$ Marie-Christine Vantyghem," \\ Jacqueline Capeau, ${ }^{\star \star \neq \|}$ and Corinne Vigouroux, ${ }^{* \dagger \neq \|}$ \\ and the Lipodystrophy Study Group
}

sis with distinct mitochondrial abnormalities but neither UCP1 expression nor prelamin A accumulation. In conclusion, Enlarged cervical scAT from patients with lipodystrophy demonstrated small adipocytes, fibrosis, and decreased vessel numbers. However, only cervical fat from patients with $L M N A$ mutations or who had received protease inhibitor therapy accumulated prelamin $A$ and exhibited similar remodeling toward a brown-like phenotype with UCP1 overexpression and mitochondrial alterations. (AmJ Pathol 2011, 179:2443-2453; DOI: 10.1016/j.ajpath.2011.07.049)

A-type lamins, encoded by the LMNA gene, are ubiquitous nuclear intermediate filament proteins involved in the structural and functional integrity of the nucleus. Mutations in LMNA cause inherited laminopathies including progeroid phenotypes and lipodystrophies, with metabolic alterations and early cardiovascular complications (reviewed in Mattout et $\mathrm{al}^{1}$ ). Among them, the Dunnigan-type familial partial lipodystrophy (FPLD2; OMIM 151660), due primarily to LMNA p.R482 heterozygous substitutions, is characterized by gradual atrophy of subcutaneous adipose tissue (scAT) in the extremities, trunk, and gluteal areas, occurring after puberty, in contrast to exces-

This work was supported by the Institut National de la Santé et de la Recherche Médicale (INSERM), the Programme National de Recherche sur le Diabète (PNRD/ARD), and the European Union's FP6 Life Science, Genomics and Biotechnology for Health LSHM-CT-2005-018690 ("Eurolaminopathies"). C.L. is a recipient of a fellowship from the Ministère Français de l'Enseignement Supérieur et de la Recherche.

Accepted for publication July 13, 2011

Additional members of the Lipodystrophy Study Group include LouiseMarie Somja-Azzi, Bruno Eymard, Barbara Antuna-Puente, Pascal Laforêt, Frédéric Tankéré, Anne Lombès, Claude Jardel, Véronique Martinot-Duquennoy, Annie-Claude Hécart, Marc Chaouat, and Maurice Mimoun

Supplemental material for this article can be found on http://ajp. amjpathol.org or at doi 10.1016/j.ajpath.2011.07.049.

Address reprint requests to Véronique Béréziat, Ph.D., Faculté de Médecine UPMC-Paris 6, INSERM UMR_S938, 27, Rue Chaligny, 75571 Paris Cedex 12. E-mail: veronique.bereziat@inserm.fr. 
Table 1. Characteristics of Patients and Controls

\begin{tabular}{|c|c|c|c|c|}
\hline Sex & Age (years) & $\mathrm{BMI}$ & $\begin{array}{l}\text { Localization of } \\
\text { collected fat }\end{array}$ & Lipodystrophy \\
\hline \multicolumn{5}{|l|}{ Controls } \\
\hline $\mathrm{F}$ & 48 & 24.5 & Anterior neck & No \\
\hline M & 69 & 23.9 & Lateral neck & No \\
\hline M & 40 & 27.5 & Anterior neck & No \\
\hline $\mathrm{F}$ & 54 & 22.1 & Anterior neck & No \\
\hline M & 82 & 24.8 & Lateral neck & No \\
\hline $\mathrm{F}$ & 87 & 23 & Anterior neck & No \\
\hline $\mathrm{F}$ & 65 & 27.3 & Anterior neck & No \\
\hline M & 62 & 23 & Anterior neck & No \\
\hline \multicolumn{5}{|c|}{ Patients with LMNA mutations } \\
\hline$F^{\star}$ & 21 & 28.7 & Anterior neck & $\begin{array}{l}\text { Lipoatrophy of lower limbs, faciocervical } \\
\text { fat accumulation }\end{array}$ \\
\hline$F^{*}$ & 28 & 23 & Anterior neck & $\begin{array}{l}\text { Lipoatrophy of lower limbs and trunk, } \\
\text { faciocervical fat accumulation }\end{array}$ \\
\hline $\mathrm{F}^{\dagger}$ & 33 & 28.3 & Anterior neck & $\begin{array}{l}\text { Lipoatrophy of lower limbs, faciocervical } \\
\text { fat accumulation }\end{array}$ \\
\hline $\mathrm{F}^{\ddagger}$ & 56 & 22.7 & Anterior neck & $\begin{array}{l}\text { Lipoatrophy of lower limbs, faciocervical } \\
\text { fat accumulation }\end{array}$ \\
\hline \multicolumn{5}{|l|}{ HIV-infected patients } \\
\hline M & 59 & 23.1 & Dorsocervical & Lipoatrophy of limbs, buffalo neck \\
\hline M & 43 & 23.7 & Dorsocervical & Lipoatrophy of limbs, buffalo neck \\
\hline M & 55 & 24.8 & Dorsocervical & Buffalo neck \\
\hline M & 55 & 26.4 & Dorsocervical & Buffalo neck \\
\hline & 44 & 41.3 & Dorsocervical & Buffalo neck \\
\hline \multicolumn{5}{|c|}{$\begin{array}{l}\text { Patients with tRNA } A^{\text {Lys }} \text { m.8344A }>G \\
\text { mtDNA mutation }\end{array}$} \\
\hline M & 52 & 33.9 & Dorsocervical & Lipomas in neck, chin, and shoulders \\
\hline M & 54 & 26 & Dorsocervical & $\begin{array}{l}\text { Lipomas in neck, scalp, chin, calves, } \\
\text { and thorax }\end{array}$ \\
\hline & & & & (table continues) \\
\hline \multicolumn{5}{|c|}{$\begin{array}{l}{ }^{*} \mathrm{p} . \mathrm{R} 482 \mathrm{~W} \text {. } \\
{ }^{\dagger} \mathrm{p} . \mathrm{R} 439 \mathrm{C} \text {. } \\
\text { Fp.H506D. } \\
\text { F, female; M, male; ARV, antiretroviral drug; HOMA-IR, homeostasis model assessment of insulin resistance; NA, not available. Nucleoside or nucleotid } \\
\text { everse transcriptase inhibitors: TDF, tenofovir; 3TC, lamivudine; ABC, abacavir; d4T, stavudine; ZDV, zidovudine. Non-nucleoside reverse transcriptas } \\
\text { hhibitor: NVP, nevirapine. Protease inhibitors: DRV, darunavir; RTV, ritonavi; IDV, indinavir. CCR5 inhibitor: MVC, maraviroc. Integrase inhibitor: RAL } \\
\text { altegravir. }\end{array}$} \\
\hline
\end{tabular}

sive adipose tissue deposition in the face, chin, and neck. ${ }^{2,3}$ The primary metabolic alterations are insulin resistance, impaired glucose tolerance or diabetes, and dyslipidemia with marked hypertriglyceridemia. ${ }^{4,5}$ Metabolic laminopathies, due to non-codon 482 LMNA mutations, are characterized by severe metabolic alterations but atypical clinical lipoatrophy. ${ }^{6}$

Although the pathophysiologic mechanisms involved in laminopathies are not fully understood, alterations in the posttranslational maturation of prelamin A are important pathogenic events. ${ }^{7-9}$ Indeed, before being assembled in the nuclear lamina as mature lamin A, prelamin A undergoes several maturation steps including addition of a farnesyl group followed by a proteolytic cleavage by the metalloprotease Zmpste24. We and others have demonstrated that FPLD2 and metabolic laminopathies are associated with an abnormal accumulation of prelamin A, possibly due to misrecognition of the mutated protein by Zmpste24. ${ }^{10,11}$ That LMNA mutations can lead to lipoatrophy in most scAT depots, but to lipohypertrophy in the faciocervical area, remains poorly understood but could be linked to differences in fat depot physiologic features. It has been suggested that prelamin A accumulation may elicit different effects in body fat areas, depending on the level of local activation of the adipogenic factor peroxisome proliferator-activated receptor- $\gamma$ (PPAR $\gamma) .^{10}$

Partial lipodystrophies with peripheral lipoatrophy but increased cervical fat (buffalo hump) are also observed in HIV-infected patients receiving antiretroviral therapy, primarily the thymidine analogues nucleoside reverse transcriptase inhibitors and HIV protease inhibitors (reviewed in Caron-Debarle et $\mathrm{al}^{12}$ ). Some protease inhibitors, in particular, ritonavir, widely used, can induce cellular prelamin A accumulation, ${ }^{11}$ via direct inhibition of the zinc metallopeptidase Zmpste24. ${ }^{13}$ Accordingly, the presence of prelamin $A$ has been observed in lipoatrophic abdominal scAT from HIV-infected patients receiving a protease inhibitorbased therapeutic regimen. ${ }^{11}$

We and others have previously reported the presence of mitochondrial abnormalities in cells and/or lipoatrophic adipose tissue from patients with LMNA mutations or HIV infection ${ }^{11,14-16}$ Moreover, patients with mutations in mitochondrial DNA (mtDNA)-encoded tRNA ${ }^{\text {Lys }}$ can develop dorsocervical non-encapsulated fat masses, ${ }^{17-19}$ which suggests that mitochondrial dysfunction could also have a role in LMNA- and HIV-linked lipodystrophies. 
Table 1. Continued

\begin{tabular}{|c|c|c|c|c|}
\hline Diabetes & HOMA-IR & $\begin{array}{l}\text { Triglycerides } \\
(\mathrm{mmol} / \mathrm{L})\end{array}$ & $\begin{array}{l}\text { Nonalcoholic } \\
\text { steatohepatitis }\end{array}$ & Other \\
\hline No & NA & NA & NA & NA \\
\hline No & NA & NA & NA & NA \\
\hline No & NA & NA & NA & NA \\
\hline No & 0.7 & 0.75 & NA & NA \\
\hline No & 1.4 & 1.5 & NA & NA \\
\hline No & 1.3 & 1.2 & NA & NA \\
\hline No & 3.9 & 1.3 & NA & NA \\
\hline No & 1.5 & 2.7 & NA & NA \\
\hline Yes & 18.1 & 3.7 & NA & No \\
\hline Yes & 13.5 & 3 & Yes & No \\
\hline Impaired glucose tolerance & 4.3 & 1.8 & Yes & Pelvic muscle weakness \\
\hline Impaired fasting glucose & 3.5 & 2.6 & No & No \\
\hline $\begin{array}{l}\text { No } \\
\text { No } \\
\text { No } \\
\text { No } \\
\text { Yes }\end{array}$ & $\begin{array}{c}\text { NA } \\
\text { NA } \\
\text { NA } \\
1.8 \\
\text { Insulin therapy }\end{array}$ & $\begin{array}{l}\text { NA } \\
\text { NA } \\
\text { NA } \\
2.2 \\
2.5\end{array}$ & $\begin{array}{l}\text { NA } \\
\text { NA } \\
\text { NA } \\
\text { NA } \\
\text { Yes }\end{array}$ & $\begin{array}{l}\text { Current ARV } \\
\text { TDF, 3TC, ABC, DRV, RTV } \\
\text { d4T, 3TC, IDV, RTV } \\
\text { ZDV, 3TC, NVP } \\
\text { TDF, 3TC, ABC } \\
\text { NVP, MVC, RAL }\end{array}$ \\
\hline $\begin{array}{l}\text { No } \\
\text { No }\end{array}$ & $\begin{array}{l}\text { NA } \\
\text { NA }\end{array}$ & $\begin{array}{l}1.7 \\
\text { NA }\end{array}$ & $\begin{array}{l}\text { NA } \\
\text { No }\end{array}$ & $\begin{array}{l}\text { Myopathy, sensory polyneuropathy } \\
\text { Myopathy }\end{array}$ \\
\hline
\end{tabular}

Thus far, histologic features of LMNA-mutated SCAT have not been reported, with the exception of an ultrastructural analysis that revealed nuclear alterations in some lipoatrophic adipocytes. ${ }^{20}$ In the present work, we studied alterations of enlarged cervical adipose tissue from patients with LMNA mutations at the histologic, immunohistologic, ultrastructural, and protein expression levels. These fat samples were compared with buffalo humps from HIV-infected patients, treated or not with protease inhibitors, with cervical lipomas due to mtDNA mutations and with cervical fat from control subjects.

\section{Materials and Methods}

\section{Subjects}

Cervical scAT samples were collected during plastic surgery in patients and during surgery performed to treat benign thyroid or parotid diseases ( $\mathrm{H}-100 \mathrm{sc}-7196)$ in eight control patients without diabetes. Four women had heterozygous $L M N A$ mutations, either $p$. R482W, leading to a typical FPLD2 phenotype, ${ }^{21,22}$ (and unpublished data) or p.R439C or p.H506D, leading to metabolic laminopathies. ${ }^{6}$ These four women demonstrated marked subcutaneous limb lipoatrophy with muscular hypertrophy and fat accu- mulation in the face and neck that had developed progressively after puberty. Lipodystrophy was associated with insulin resistance and hypertriglyceridemia. We also collected accumulated dorsocervical fat samples (buffalo humps) from five HIV-infected men currently receiving ( $n=$ 2) or not receiving $(n=3)$ protease inhibitor-based antiretroviral therapy. These patients developed mixed lipodystrophy with peripheral lipoatrophy but increased dorsocervical fat. In addition, two unrelated men were referred because of myopathy and multiple lipomatosis due to the mtDNA tRNA ${ }^{\text {Lys }}$ m. 8344A $>$ G mutation ${ }^{18}$ (and unpublished data). Both men underwent surgical removal of a large dorsocervical lipoma, clinically similar to a buffalo hump. ${ }^{18}$ Characteristics of patients and control subjects are given in Table 1. Informed consent was obtained from all patients and control subjects, according to our local ethics committee.

\section{Adipose Tissue Histology}

Light microscopy and immunohistochemical studies were performed as previously described. ${ }^{23}$ In brief, light microscopy was performed using 10\% zinc-formol-fixed paraffin-embedded 5-mm tissue sections stained with hemalum-phloxine for morphologic studies and with Sirius Red to detect collagen fibers. The 


\section{Controls}

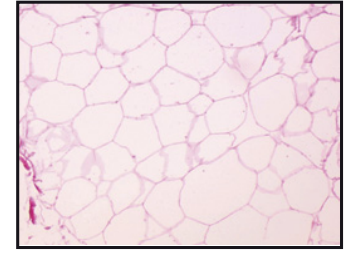

FPLD LMNA p.R482W

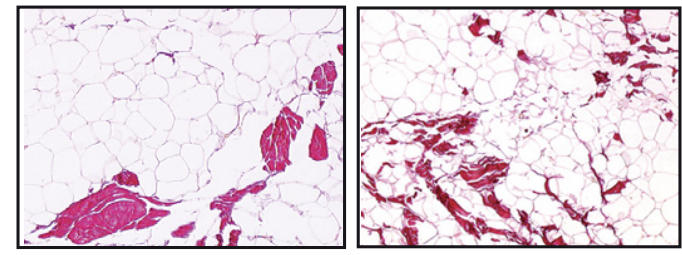

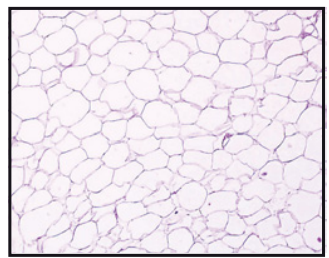

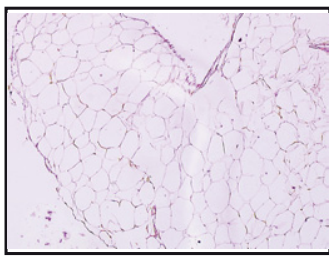

Metabolic Laminopathies LMNA p.H506D LMNA p.R439C
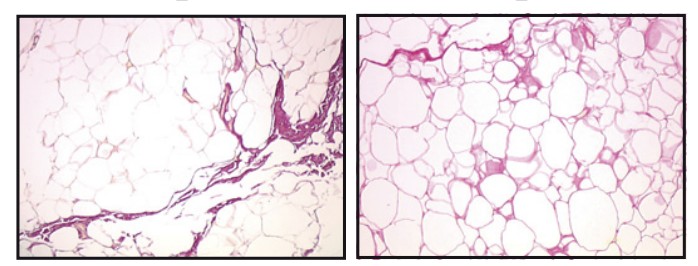

PI-treated

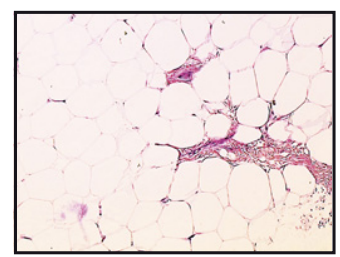

\section{HIV-infected patients}

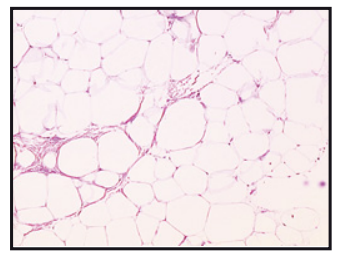

Non PI-treated

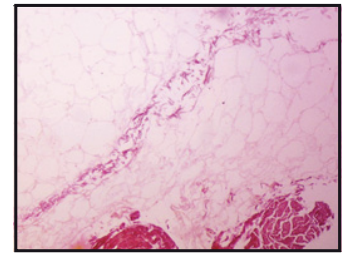

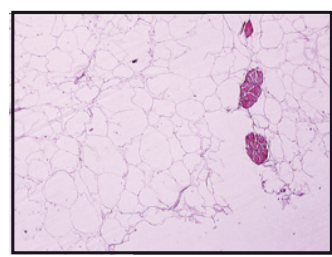

mtDNA-mutated lipomas tRNALys m.8344A>G
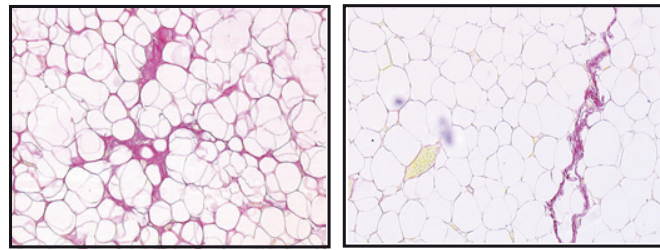

Figure 1. Cervical fat from patients with $L M N A$ - or HIV-related lipodystrophies or with mitochondrial lipomatosis demonstrates a dystrophic phenotype with fibrosis. Light microscopy analysis of cervical adipose tissue, stained with Sirius Red to detect collagen fibers. Representative photographs are shown. Adipose tissue (magnification, $\times 10$ ) from patients with $L M N A$-linked and HIV-related lipodystrophies or with mtDNA mutated lipomas had a heterogeneous structure with clusters of small adipocytes. Note the excess of fibrosis in patient samples as compared with control samples, with bundles of fibrosis in FPLD2.

adipocyte mean areas, index of fibrosis, and number of lipogranulomas were determined using a semi-automatic image analysis system (Mercator; Explora Nova, La Rochelle, France) in three randomly chosen regions. The ratio of fibrosis to total adipose tissue surfaces defined the index of fibrosis.

For immunohistochemical studies, tissue sections were probed using antibodies directed against the proinflammatory macrophages marker CD68 $23-25$ (1:300; Dako Corp., Carpenteria, CA), the inflammatory cytokines IL-6 (IL6, MAB206 1:50) and tumor necrosis factor- $\alpha$ (hTNF $\alpha$, MAB610 1:50) (both from R\&D Systems Europe, Ltd., Abingdon, Oxfordshire, England), the mitochondrial respiratory chain proteins cytochrome c oxidase subunits 2 (COX2) and 4 (COX4) (A-6404, 1:100 and A-21348, 1:100; Molecular Probes, Inc., Eugene, OR), a mitochondrial antigen (MU213-UC, 1:50; BioGenex Laboratories, Inc., San Ramon, CA), and the vascular marker CD34 (endothelial cells) (clone QBEnd-10) and $\alpha$-smooth muscle actin $(\alpha-S M A$, staining the media layer of arteries, clone 1A4) (both from Dako SA, Trappes, France).

Ultrastructural analysis was performed on fat samples fixed in $2.5 \%$ glutaraldehyde in $0.1 \mathrm{mmol} / \mathrm{L}$ cacodylate buffer $(\mathrm{pH}$ 7.4 ) at $4^{\circ} \mathrm{C}$. Fragments were then post-fixed in $1 \%$ osmium tetroxide, dehydrated using graded alcohol series, and embedded in epoxy resin. Semi-fine sections $(0.5 \mu \mathrm{m})$ were stained using toluidine blue. Ultrastructure sections $(60 \mathrm{~nm})$ were contrast-enhanced using uranyl acetate and lead citrate, and examined using a JEOL 1010 electron microscope (JEOL, Ltd., Tokyo, Japan) with a MegaView III camera (Olympus Soft Imaging Systems GmbH, Münster, Germany).

\section{mRNA Assays}

Total RNA was extracted from samples stored in liquid nitrogen using the RNeasy Lipid Tissue Minikit (Qiagen SA, 
Courtaboeuf, France). mRNA expression was measured using real-time RT-PCR on the LightCycler system (Roche Diagnostics France SA, Meylan, France), as previously described. ${ }^{25}$ The following primers were used: for TATA-binding protein (used as an internal standard for mRNA expression): forward, 5'-GCTCACCCACCAACAATTTAG-3', and reverse, 5'-GAGCCATTACGTCGTCTTCC-3'; and for CD68: forward, 5'-TCAGCTTTGGATTCATGCAG-3', and reverse, 5' AGGTGGACAGCTGGTGAAAG-3'.

\section{Western Blot Analysis}

Frozen fat tissue ( $300 \mathrm{mg}$ ) was solubilized in $500 \mu \mathrm{L} 2.5 \mathrm{X}$ Laemmli buffer containing $150 \mathrm{mmol} / \mathrm{L}$ dithiotreitol. Lysates were subjected to SDS-PAGE, blotted onto nitrocellulose membranes, and probed using antibodies directed against the adipocyte transcription factors PPAR $\gamma$, sterol regulatory element-binding protein 1 (SREBP-1) (K-10 sc-367) and prelamin A (sc-6214) (all from Santa Cruz Biotechnology, Inc., Santa Cruz, CA), lamin A/C (MAB-3211; Chemicon International, Inc., Temecula, CA), COX2 and COX4 (A-6404 1:100 and A-21348, 1:100; Molecular Probes, Inc.), mitochondrial voltage-dependent anion channel (VDAC/porin, Ab-5 PC548; Merck KGaA, Darmstadt, Germany), and UCP1 (ab10983; Abcam, Ltd., Cambridge, England). The antibodies were detected using a chemiluminescence detection kit (Amersham Pharmacia Biotech SA, Les Ulis, France). $\beta$-Actin (A5441; Sigma-Aldrich Corp., St. Louis, MO) was used as an index of the cellular protein level.

Quantifications, normalized to $\beta$-actin expression, were performed by using the ChemiGenius2 image analyzer and software (Ozyme, St. Quentin en Yvelines, France), and were expressed in fold changes versus control.

\section{Statistical Analysis}

All results were from triplicate experiments, and are expressed as mean \pm SEM.

\section{Results}

\section{Patient Cervical Adipose Tissue Presents a Dystrophic Phenotype with Fibrosis but No Inflammation}

In the eight controls, fat samples were composed of several lobules with mature univacuolar adipocytes delineated by sharp thin capsules without fibrosis, as evidenced at Sirius Red staining. The disposition and size of control adipocytes were overall homogeneous (Figure 1). In contrast, adipose tissue from patients with LMNA mutations, HIV infection, receiving protease inhibitor therapy or not, or mtDNA mutations had a heterogeneous structure with clusters of small or normal-sized adipocytes (Figure 1). In addition, marked fibrosis was present in cervical scAT from all patients and demonstrated fibrotic bundles and/or fibrotic thickening of fat lobules (Figure 1). These areas did not represent scar fat because the patients had not undergone previous fat surgery.
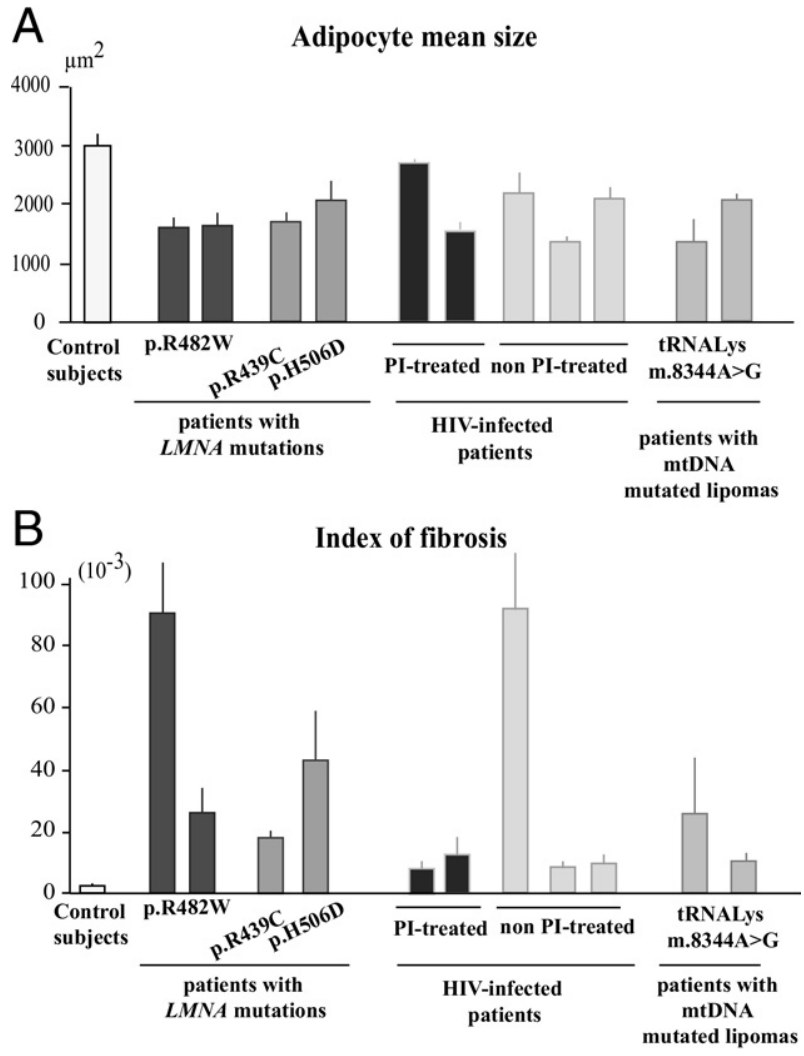

Figure 2. Quantification of adipocyte size and of fibrosis in cervical fat from patients and control subjects. Adipocyte size (A) and index of fibrosis (B) in cervical adipose tissue from control subjects and patients with FPLD2, metabolic laminopathies, HIV-linked lipodystrophy either protease inhibitortreated or not, and mtDNA mutated lipomas. All results were obtained from triplicate measurements and are expressed as mean \pm SEM for the control group and each patient.

In agreement with these observations, the mean adipocyte size measured in patient cervical fat was lower than in control fat (ie, 1734, 1968, and $1692 \mu \mathrm{m}^{2}$ for patients with LMNA mutations, HIV infection, or mtDNA mutations, respectively, versus $2988 \mu \mathrm{m}^{2}$ for control subjects) (Figure 2A). In addition, a higher index of fibrosis was observed in fat from all patients as compared with control subjects (ie, 44.5, 25.6, and 17.5 for patients with LMNA mutations, HIV infection, or mtDNA mutations, respectively, versus 2.9 for control subjects) (Figure 2B).

At the ultrastructural level, control cervical scAT demonstrated adipocytes with thin and regular cytoplasm and small intercellular areas. In fat from all patients, irregular cell outlines were observed, with thickened peripheral rims of cytoplasm and interstitial edema with compact and thick fibrils of collagen invading the intercellular area (Figure 3).

In samples from control subjects and patients with LMNA or HIV-linked lipodystrophy, only rare macrophages were observed. Accordingly, in these cases, only a few cells were stained with CD68, a marker of proinflammatory macrophages (Figure 4A). In addition, mRNA expression of CD68 and labeling of the proinflammatory cytokines IL- 6 and TNF- $\alpha$ was similar in cervical fat from 


\section{Controls}
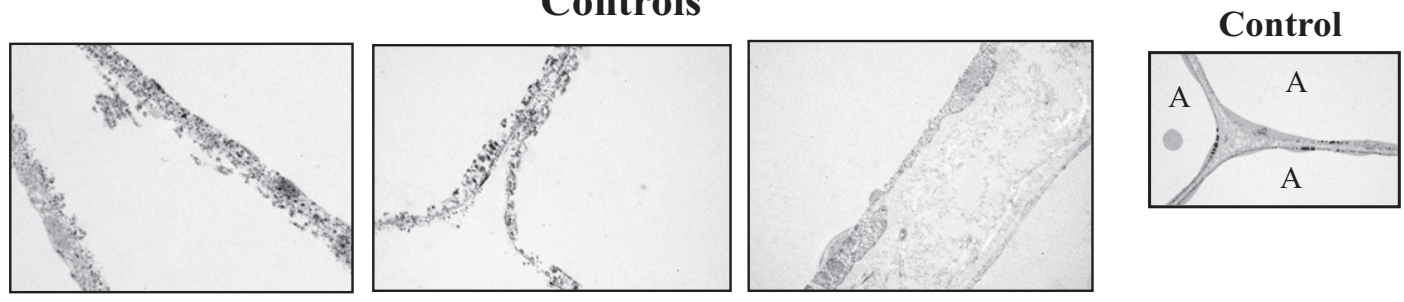

FPLD LMNA p.R482W
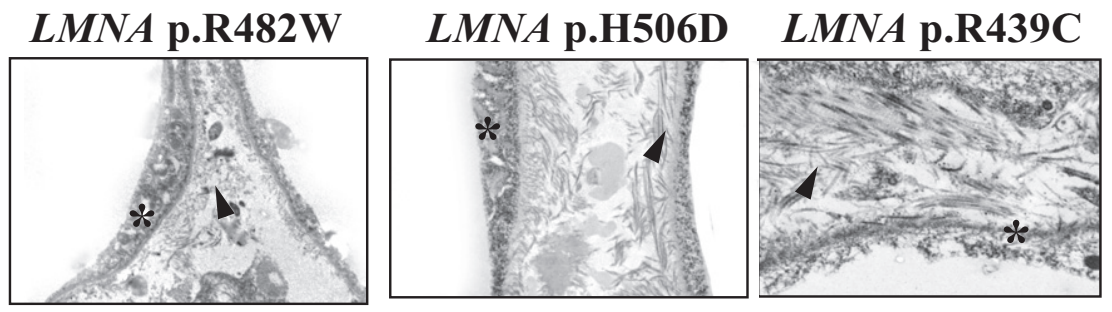

Metabolic Laminopathies Metabolic Laminopathy

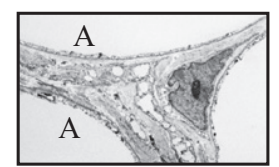

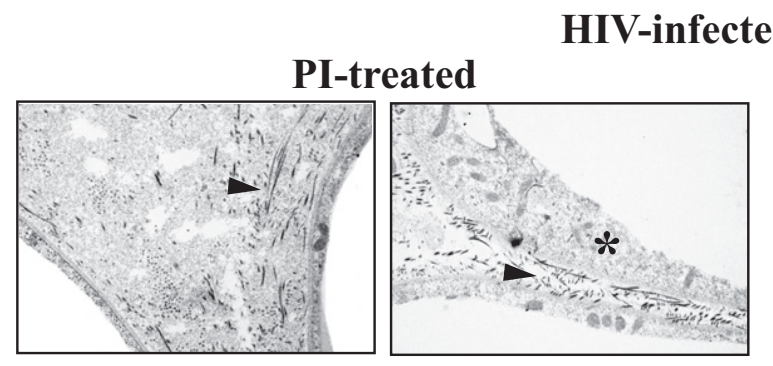

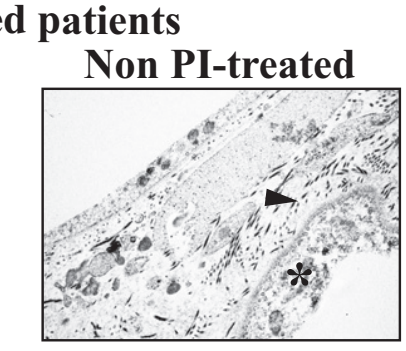

\section{mtDNA mutated lipomas \\ tRNALys m.8344A>G}
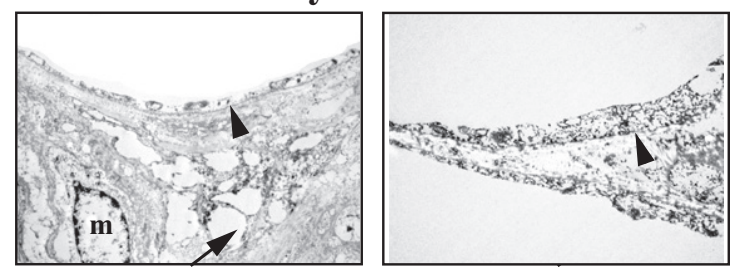

Figure 3. Electron microscopy analysis of cervical adipose tissue from patients with $L M N A$-linked or HIV-related lipodystrophies or mtDNA mutations reveals intercellular fibrosis. Cervical adipose tissue from control subjects showed thin and regular cytoplasm and light intercellular areas. In contrast, thickened peripheral rims of cytoplasm (stars) and compact and thick fibrils of collagen invading the intercellular area (arrowheads) were observed in fat from patients. Large fat droplets lying free in the connective tissue (arrow) and numerous macrophages $(\mathrm{m})$ were observed in mtDNA-mutated lipomas. A, adipocyte. Magnification, $\times 20,000$, except for far right column $\times 5000$.

patients with LMNA mutations or HIV infection and from control subjects (data not shown).

Conversely, in the mtDNA-mutated lipomas, ultrastructural analysis revealed adipocytes with disrupted cell membranes, variably fragmented cytoplasmic rims, and large fat droplets lying free in the connective tissue, with numerous macrophages (Figure 3). Accordingly, in these samples, we observed many lipogranulomas, ie, CD68-positive macrophages organized into crown-like structures surrounding involutionary adipocytes (Figure 4, A and B), and CD68 mRNA expression was increased as compared with that in control samples (data not shown).

In contrast to data previously reported in lipoatrophic areas from patients with $L M N A$ mutations, ${ }^{20}$ we did not detect ultrastructural alterations in the nucleus architec- ture of cervical adipocytes in the patients with LMNA mutations (data not shown).

Considered together, these data demonstrate that the dystrophic phenotype of enlarged cervical adipose tissue is not associated with inflammatory features in patients with lipodystrophy with LMNA mutations or HIV infection.

\section{Patient Cervical Adipose Tissue Demonstrates Fewer Vessels Than Does Control Fat}

As shown in Figure 5, the surface occupied by blood vessels was decreased in patient samples as compared with control samples, as assessed using immu- 
A

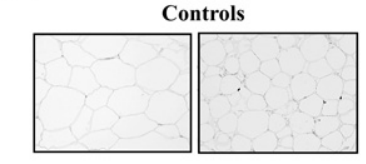

mtDNA mutated lipomas tRNALys m.8344A $>$ G

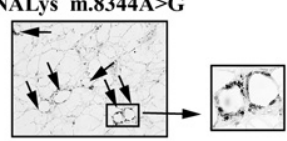

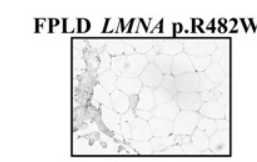

Metabolic Laminopathies LMNA P.R439C LMNA p.H506D

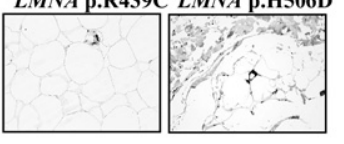

HIV-infected patients PI-treated Non PI-treated

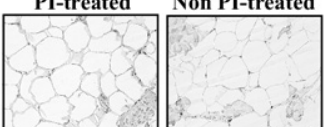

B

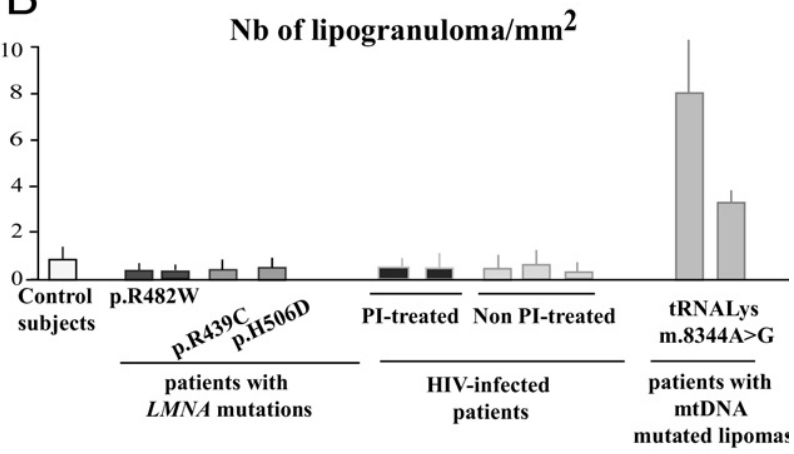

Figure 4. Enlarged cervical fat from patients with $L M N A$ - or HIV-related lipodystrophies does not exhibit inflammatory features. A: Tissue sections were probed using antibodies directed against CD68, a marker of proinflammatory macrophages. Note the presence of crown-like structures surrounding involutionary adipocytes (ie, lipogranulomas) in lipomas from patients with mtDNA mutations (arrows). Magnification, $\times 20$. B: Quantitative analysis of lipogranulomas. Results were obtained from triplicate measurements and are expressed as mean \pm SEM for each subject. The number of lipogranulomas was high in fat from mtDNA-mutated lipomas but low in cervical fat from control subjects and patients with $L M N A$ mutations or HIV infection.

nohistologic staining with the endothelial cells marker CD34. In addition, the surface occupied by small arteries, stained using $\alpha$-SMA, was also decreased in all patient samples as compared with control samples (data not shown, and Figure 5B). The results were similar when we evaluated the number of vessels and small arteries in the adipose tissue areas excluding fibrosis (data not shown).

\section{Enlarged Cervical Adipose Tissue from Patients with LMNA Mutations or Protease Inhibitor-Treated HIV Infection Demonstrates Altered Expression of Adipogenic Factors, Increased UCP1 Level, and Prelamin A \\ Accumulation}

The adipogenic transcription factors SREBP-1 and PPAR $\gamma$ revealed the same altered pattern of protein expression in patients with LMNA mutations or protease inhibitor-treated HIV infection: SREBP-1 was increased and PPAR $\gamma$ was underexpressed as compared

with control samples (Figure 6). In buffalo humps from HIV-infected patients without current protease inhibitor treatment, expression of adipogenic genes was not significantly different from that in control subjects. In contrast, mtDNA-mutated lipomas demonstrated a decrease in SREBP-1 protein expression as compared with control fat.

Prelamin A accumulation was specific of samples from patients with LMNA mutations or HIV infection receiving protease inhibitor-based therapy (Figure 6), whereas expression of mature lamin $A$ and lamin $C$ in these patients was not different from that in control subjects (data not shown).

In addition, sustained increased UCP1 expression was observed in cervical fat from patients with LMNA mutations or protease inhibitor-treated HIV infection, but not in control subjects or in patients with mtDNA mutations or with HIV infection without current protease inhibitor therapy (Figure 6).

Altogether, these results indicate that enlarged cervical scAT from patients with LMNA mutations or protease inhibitor-treated HIV infection presents a specific phenotype with altered expression of adipogenic factors associated with UCP1 overexpression and prelamin A accumulation.
A

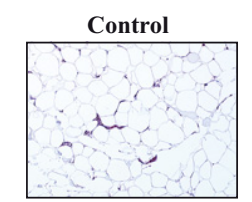

mtDNA mutated lipoma tRNALys $m .8344 \mathrm{~A}>\mathrm{G}$

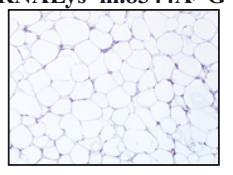

B

aSMA staining surface $/ \mathrm{mm}^{2} \quad \mathrm{CD} 34$ staining surface $/ \mathrm{mm}^{2}$
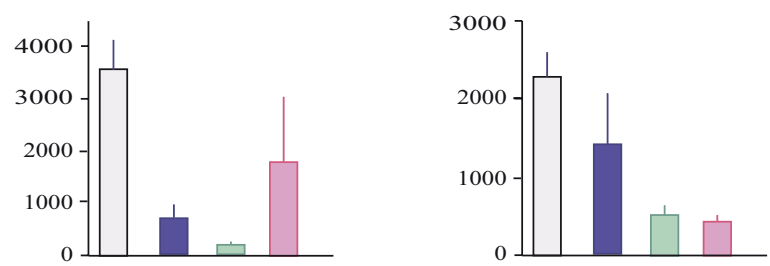

Figure 5. Patient cervical fat demonstrates a decreased number of vessels as compared with fat from control subjects. A: Tissue sections were probed using antibodies directed against CD34, a marker of endothelial cells. Magnification, $\times 20$. B: Quantification of $\alpha$-SMA (a marker of the media layer of arteries) and CD34-stained surfaces in samples from control subjects and from patients with $L M N A$ mutations (blue), HIV infection (green), or mtDNA mutations (pink) 

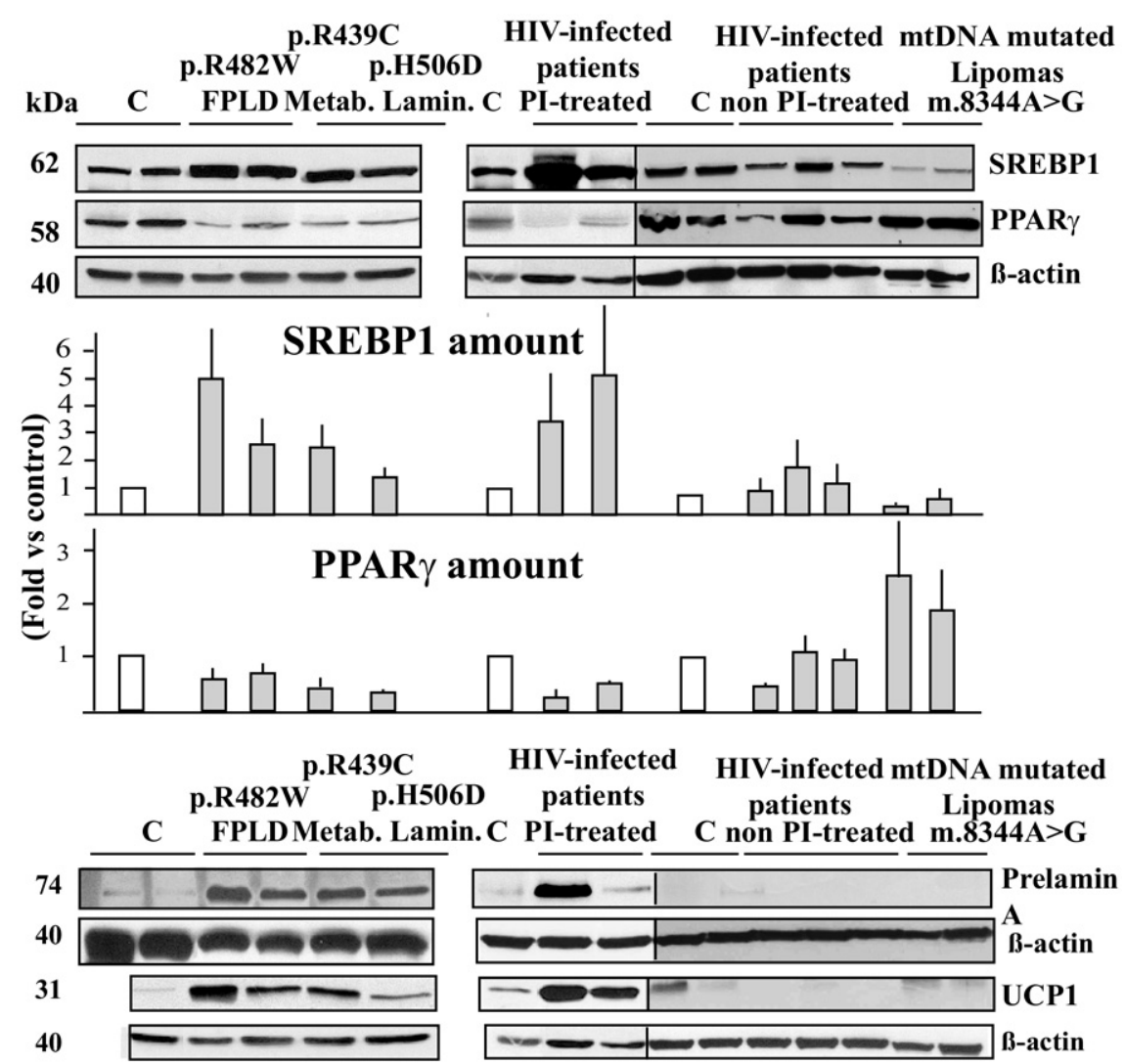

Prelamin A amount

(Fold vs control)

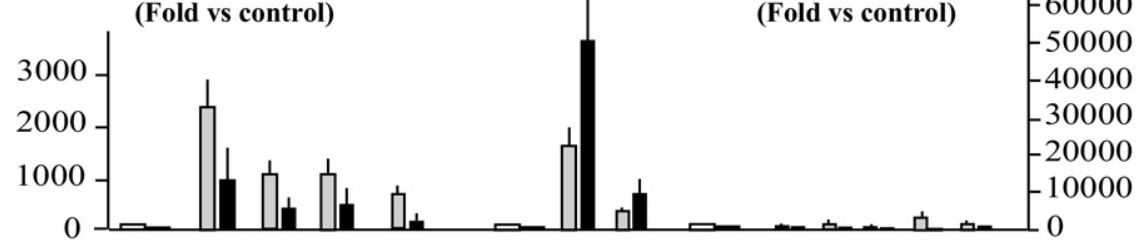

Figure 6. Cervical adipose tissue from patients with $L M N A$ mutations or HIV infection currently treated using protease inhibitors demonstrates altered adipogenic factors and increased UCP1 expression with prelamin A accumulation. Adipose tissue lysates were submitted to Western blot analysis using antibodies directed against SREBP-1, $\operatorname{PPAR} \gamma$, prelamin A, UCP1, or $\beta$-actin (used as an index of total protein expression). Representative blots from triplicate experiments are shown, and quantifications are expressed as fold changes versus control values. The accumulation of prelamin A is associated with increased expression of UCP1 in enlarged cervical fat from patients with $L M N A$ mutations or HIV infection treated using a protease inhibitor-based therapeutic regimen. C, control subject fat samples.
Enlarged Cervical Adipose Tissue from Patients with LMNA Mutations or HIV Infection with Protease Inhibitor-Based Therapy Demonstrates Brown Fat-Like Features with Increased Mitochondrial Density

Ultrastructural analyses evidenced an increased number of mitochondria in enlarged cervical scAT from patients with LMNA mutations or with HIV infection receiving current protease inhibitor therapy as compared with control subjects (Figure 7A). The density of mitochondria was even higher in mtDNA-mutated lipomas, which was confirmed at immunohistologic staining (Figure 7B).

However, the protein expression of the voltage-dependent anion channel (VDAC/porin), a marker of the mitochondrial outer membrane, and the mtDNA-encoded subunit 2 of the respiratory chain complex IV (COX2) were decreased in patients with LMNA mutations or HIV infection receiving current protease inhibitor treatment, as compared with control subjects (Figure 8). In mtDNA- mutated lipomas, overexpression of VDAC/porin was observed, with reduced protein expression of COX2, whereas nuclear encoded protein COX4 was compensatorily overexpressed (Figure 8; see also Supplemental Figure S1 at http://ajp.amjpathol.org). In samples from HIV-infected patients not receiving protease inhibitor treatment, mitochondria were not increased, and VDAC/ porin and COX2 expression were decreased or similar to that in controls.

Considered together, these results provide evidence that enlarged cervical adipose tissue from patients with LMNA mutations or protease inhibitor-treated HIV infection exhibits brown fat-like features which associates increased mitochondria density and increased UCP1 expression.

\section{Discussion}

The present study revealed that accumulated cervical fat in patients with lipodystrophy is not due to a simple com- 
A
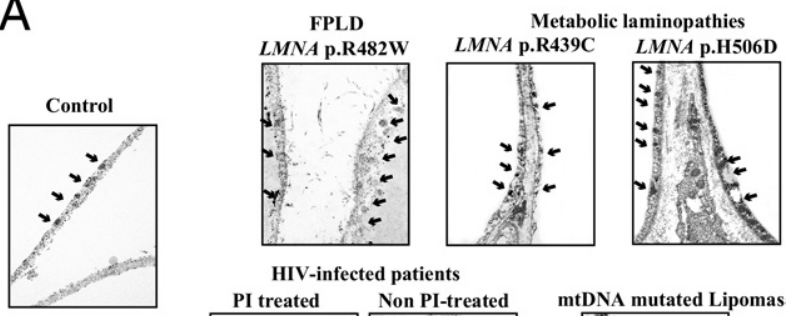

HIV-infected patients

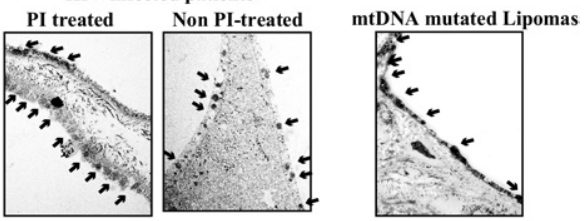

B
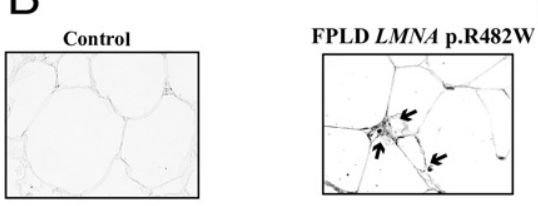

Metabolic Laminopathies

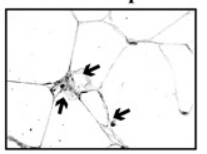

HIV-infected patients
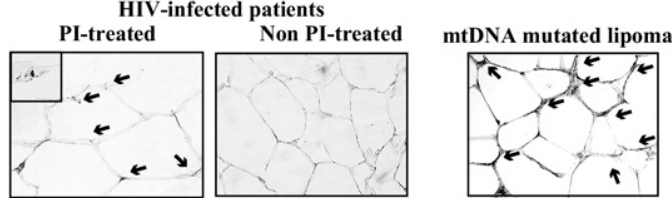

Figure 7. Cervical adipose tissue from patients with $L M N A$ mutations or protease inhibitor-based treated HIV infection demonstrates an increased number of mitochondria. Electron microscopy analysis (magnification, $\times 20,000)(\mathbf{A})$ and immunohistochemical analysis using antibodies directed against mitochondria (magnification, $\times 40)(\mathbf{B})$ in cervical adipose tissue samples. Increased density of mitochondria (arrows) was observed in all patient samples, but was maximal in mtDNA-mutated fat.

pensatory increase in triglyceride stores but to a peculiar structural remodeling of adipose tissue with small adipocytes and fibrosis. In addition, enlarged cervical scAT from patients with LMNA mutations or HIV-infection treated using protease inhibitor-based therapy demonstrates a highly similar phenotype exhibiting some brown fat-associated characteristics.

The pathophysiologic mechanisms of partial lipodystrophies, leading to lipoatrophy in some body areas together with fat accumulation in other fat depots, have not been clearly defined. Insofar as lipoatrophy, in patients with LMNA mutations or who received HIV antiretroviral therapy, it has been proposed that it could result from altered expression of adipogenic factors, ${ }^{10,20}$ premature cellular aging, ${ }^{11,26}$ mitochondrial alterations with oxidative stress $^{11,14,15}$, and low-grade adipose tissue inflammation. ${ }^{25}$ However, to date, the pathophysiology of increased cervical fat in partial lipodystrophies has not been defined.

We observed similar alterations in patients with LMNA mutations or HIV infection treated with protease inhibitorbased therapy. First, fat tissue architecture was similarly altered, with adipocytes of heterogeneous and reduced size and noninflammatory fibrosis without increased angiogenesis. Second, cervical fat demonstrated accumulation of prelamin A and altered expression of adipogenic factors, with increased SREBP-1 and decreased PPAR $\gamma$. Third, enlarged cervical fat tissue demonstrated mito- chondrial proliferation with altered expression of several mitochondrial proteins, and enhanced UCP1 expression, which suggests that some adipocytes, although univacuolar, could develop a brown-like phenotype in both situations. However, the observation that despite severe mitochondrial dysfunction there is no prelamin A accumulation and UCP-1 expression in samples from patients with mtDNA mutations suggests that increased prelamin A and UCP-1 expression are independent of mitochondrial dysfunction.

Thus, prelamin A accumulation without defects in expression of A-type lamins, which occurs secondary to LMNA mutations or protease inhibitor therapy ${ }^{10,11}$, could be an important initial pathophysiologic event involved in the abnormalities observed in enlarged cervical scAT from patients with LMNA mutations or HIV infection treated using protease inhibitor-based therapy. In vitro, prelamin A sequesters SREBP-1 at the adipocyte nuclear envelope, leading to decreased PPAR $y$ expression and altered adipocyte differentiation. ${ }^{10,27}$ However, Guallar et $\mathrm{al}^{28}$ did not observe decreased PPAR $\gamma$ expression in buffalo humps in HIV-infected patients. In their study, buffalo hump samples were compared with abdominal control scAT, ${ }^{28}$ whereas in the present study, cervical control scAT was used. Accumulation of prelamin A was also reported in lipoatrophic fat from patients with $L M N A$ mutations, with decreased PPAR-gamma mRNA expression at the thigh level. ${ }^{20}$ In transgenic p.R482Q-LMNA mice, epididymal fat pads also demonstrated heterogeneous adipocyte size and decreased PPARG gene expression. ${ }^{29}$ Therefore, LMNA mutations could lead to similar alterations in adipogenic gene expression in both lipoatrophic and enlarged fat regions.

Buffalo humps from HIV-infected patients not currently receiving protease inhibitor therapy exhibited a

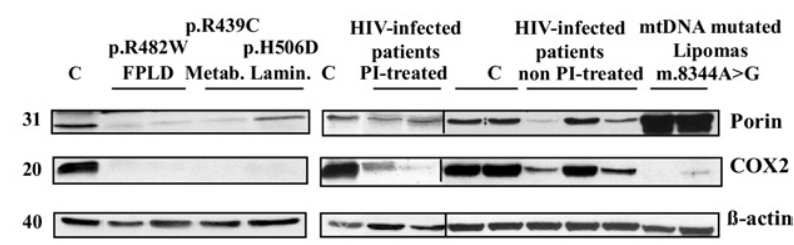

kDa

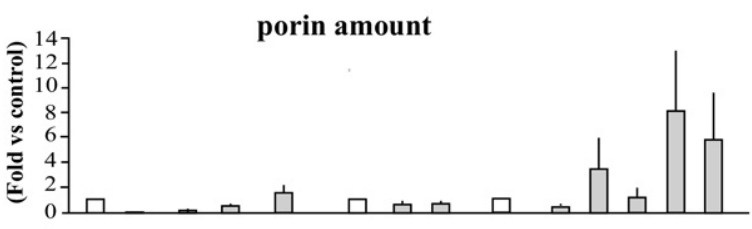

COX2 amount

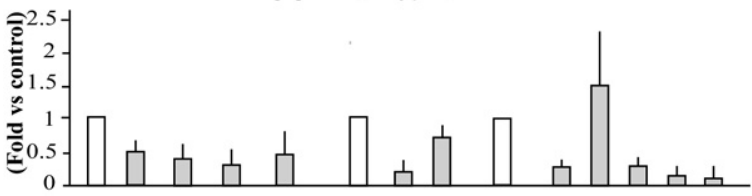

Figure 8. Patient cervical fat demonstrates alterations of mitochondrial protein expression. Adipose tissue lysates were submitted to Western blot analysis using antibodies directed against the mitochondrial proteins VDAC/porin, COX2 (mtDNA-encoded), and $\beta$-actin, used as an index of total protein expression. Representative blots from triplicate experiments are shown, and quantifications are expressed as fold changes versus control values. C, control subject fat samples. 
similar dystrophic pattern, although without major alterations in the level of adipogenic factors and mitochondrial proliferation and without increased prelamin A and UCP1 expression. Cervical fat masses due to mtDNA mutations exhibit distinctive features, with inflammatory fibrosis and, as previously described, ${ }^{30}$ a dramatic compensatory increase in mitochondrial density, in the absence of prelamin A accumulation or UCP1 expression, previously reported as highly variable between patients. ${ }^{17,19}$

Of note, vascular and skin tissues from patients with LMNA-linked progeria, characterized by defects in prelamin A maturation, demonstrated fibrotic features. ${ }^{31,32}$ In addition, human p.L59R LMNA-mutated fibroblasts did not demonstrate the physiologic decrease in collagen production during aging. ${ }^{33}$ Therefore, $L M N A$ mutations and/or altered prelamin A maturation could lead to altered extracellular matrix production, which could participate in adipose tissue dystrophy. However, inasmuch as we observed that adipose tissue fibrosis was also present in mtDNA-mutated lipomas and in buffalo humps from patients not treated using protease inhibitors, a role for prelamin $A$ in that setting is not likely.

A role for local inflammation in adipose tissue fibrosis in obese patients has been proposed. ${ }^{34}$ Indeed, inflammatory alterations of adipose tissue are now recognized as important determinants in the metabolic complications of obesity, ${ }^{35}$ and studies of adipose tissue from obese patients strongly suggest that activated macrophages secreting inflammatory cytokines could lead to excessive synthesis of extracellular matrix components by adipocytes. In addition, hypoxia is considered an initiator of obesity-linked adipose tissue fibrosis. ${ }^{34,36}$ Our results favor distinct pathophysiologic mechanisms in enlarged cervical fat associated with LMNA mutations or HIV infection. Indeed, we have observed a decreased number of vessels but no increased inflammation. Accordingly, previous reports have demonstrated that mRNA expression of inflammatory genes was unaltered in buffalo humps in HIV-infected patients, ${ }^{28}$ and expression of inflammatory genes was significantly lower in dorsocervical versus abdominal scAT in HIV-infected patients with lipodystrophy. ${ }^{37}$

Recent studies have provided evidence for the presence of brown adipocytes in cervical fat from adult control subjects, characterized by numerous mitochondria expressing UCP1 (reviewed in Fontini and $\mathrm{Cinti}^{38}$ ). In dorsocervical fat or buffalo humps in HIV-infected patients, conflicting results have been reported insofar as mtDNA content and UCP1 mRNA expression. ${ }^{28,37,39}$ The present study provides new data that could explain, in part, these discrepancies, because we observed that only buffalo humps in patients receiving protease inhibitor-based therapy demonstrated UCP1 overexpression.

A white-to-brown adipocyte transdifferentiation was proposed to occur inside of some white fat depots. ${ }^{40-42}$. Of note, brown fat from LMNA-mutated FPLD mice demonstrated a white-like appearance, which was presumed to be due to the reduced potential of adipose precursor cells. ${ }^{29}$ Therefore, one hypothesis, which needs further investigation, could be that prelamin A accumulation could participate in the transdifferentiation process of white to brown adipocytes.

The present study has some limitations. Few patients were included, and the study design was cross-sectional. Patients were of different sexes according to their underlying disease. However, when we compared the results obtained in male and female control subjects, we did not observe significant differences (data not shown). In addition, we did not perform any in vivo or ex vivo measurements to translate the clinical relevance of the increased level of UCP1.

In conclusion, enlarged cervical SCAT in patients with either LMNA mutations or HIV infection with protease inhibitor-based therapy presents a peculiar but similar structural remodeling of adipose tissue with brown fat-like features. Accumulation of prelamin A, observed in both groups of patients, probably resulted in UCP1 expression through unknown mechanisms. Increased fibrosis, decreased vessel numbers and adipocyte size, and mitochondrial dysfunction in the absence of inflammation were also observed, independent of prelamin $\mathrm{A}$ accumulation and UCP1 overexpression, this phenotype being different from that reported in abdominal subcutaneous fat from patients with lipoatrophy or obesity.

\section{Acknowledgments}

We thank the patients, Drs. Frédéric Sauveur Sarfati, Philippe Levan, Gilbert Zakine, and Aurélie Decaudain for providing surgical samples of adipose tissue.

\section{References}

1. Mattout A, Dechat T, Adam SA, Goldman RD, Gruenbaum Y: Nuclear lamins, diseases and aging. Curr Opin Cell Biol 2006, 18:335-341

2. Cao H, Hegele RA: Nuclear lamin A/C R482Q mutation in Canadian kindreds with Dunnigan-type familial partial lipodystrophy. Hum Mol Genet 2000, 9:109-112

3. Shackleton S, Lloyd DJ, Jackson SN, Evans R, Niermeijer MF, Singh BM, Schmidt $H$, Brabant G, Kumar S, Durrington PN, Gregory S, O'Rahilly S, Trembath RC: LMNA, encoding lamin A/C, is mutated in partial lipodystrophy. Nat Genet 2000, 24:153-156

4. Vigouroux C, Caron-Debarle M, Le Dour C, Magré J, Capeau J: Molecular mechanisms of human lipodystrophies: from adipocyte lipid droplet to oxidative stress and lipotoxicity. Int J Biochem Cell Biol 2011, 43:862-876

5. Garg A, Agarwal AK: Lipodystrophies: disorders of adipose tissue biology. Biochim Biophys Acta 2009, 1791:507-513

6. Decaudain A, Vantyghem MC, Guerci B, Hecart AC, Auclair M, Reznik Y, Narbonne H, Ducluzeau PH, Donadille B, Lebbé C, Béréziat V, Capeau J, Lascols O, Vigouroux C: New metabolic phenotypes in laminopathies: LMNA mutations in patients with severe metabolic syndrome. J Clin Endocrinol Metab 2007, 92:4835-4844

7. Navarro CL, Cau P, Lévy N: Molecular bases of progeroid syndromes. Hum Mol Genet 2006, 15(Spec No 2):R151-R161

8. Worman HJ, Fong LG, Muchir A, Young SG: Laminopathies and the long strange trip from basic cell biology to therapy. J Clin Invest 2009, 119:1825-1836

9. Rodriguez S, Eriksson M: Evidence for the involvement of lamins in aging. Curr Aging Sci 2010, 3:81-89

10. Capanni C, Mattioli E, Columbaro M, Lucarelli E, Parnaik VK, Novelli G, Wehnert M, Cenni V, Maraldi NM, Squarzoni S, Lattanzi G: Altered pre-lamin A processing is a common mechanism leading to lipodystrophy. Hum Mol Genet 2005, 14:1489-1502

11. Caron M, Auclair M, Donadille B, Béréziat V, Guerci B, Laville M, Narbonne H, Bodemer C, Lascols O, Capeau J, Vigouroux C: Human 
lipodystrophies linked to mutations in A-type lamins and to HIV protease inhibitor therapy are both associated with prelamin A accumulation, oxidative stress and premature cellular senescence. Cell Death Differ 2007, 14:1759-1767

12. Caron-Debarle M, Lagathu C, Boccara F, Vigouroux C, Capeau J: HIV-associated lipodystrophy: from fat injury to premature aging. Trends Mol Med 2010, 16:218-229

13. Hudon SE, Coffinier C, Michaelis S, Fong LG, Young SG, Hrycyna CA: HIV-protease inhibitors block the enzymatic activity of purified Ste24p. Biochem Biophys Res Commun 2008, 374:365-368

14. Villarroya J, Giralt M, Villarroya F: Mitochondrial DNA: an up-andcoming actor in white adipose tissue pathophysiology. Obesity 2009 $17: 1814-1820$

15. De Pauw A, Tejerina S, Raes M, Keijer J, Arnould T: Mitochondria (dys)function in adipocyte (de)differentiation and systemic metabolic alterations. Am J Pathol 2009, 175:927-939

16. Hammond E, McKinnon E, Nolan D: Human immunodeficiency virus treatment-induced adipose tissue pathology and lipoatrophy: prevalence and metabolic consequences. Clin Infect Dis 2010, 51:591-599

17. Vila MR, Gamez J, Solano A, Playan A, Schwartz S, Santorelli FM, Cervera C, Casali C, Montoya J, Villarroya F: Uncoupling protein-1 mRNA expression in lipomas from patients bearing pathogenic mitochondrial DNA mutations. Biochem Biophys Res Commun 2000, 278:800-802

18. Auré K, Sternberg D, Maisonobe T, Herson S, Jardel C, Blondy P Lombès A, Eymard B, Laforêt P: Myopathy-lipomatosis associated with A8344G mitochondrial DNA mutation. Rev Neurol (Paris) 2003, 159:1163-1168

19. Guallar JP, Vila MR, Lopez-Gallardo E, Solano A, Domingo JC, Gamez J, Pineda M, Capablo JL, Domingo P, Andreu AL, Montoya J, Giralt M, Villarroya F: Altered expression of master regulatory genes of adipogenesis in lipomas from patients bearing tRNA(Lys) point mutations in mitochondrial DNA. Mol Genet Metab 2006, 89:283-285

20. Araujo-Vilar D, Lattanzi G, Gonzalez-Mendez B, Costa-Freitas AT, Prieto D, Columbaro M, Mattioli E, Victoria B, Martinez-Sanchez N, Ramazanova A, Fraga M, Beiras A, Forteza J, Dominguez-Gerpe L, Calvo C Lado-Abeal J: Site-dependent differences in both prelamin $\mathrm{A}$ and adipogenic genes in subcutaneous adipose tissue of patients with type 2 familial partial lipodystrophy. J Med Genet 2009, 46:40-48

21. Vigouroux C, Magré J, Vantyghem MC, Bourut C, Lascols O, Shackleton S, Lloyd DJ, Guerci B, Padova G, Valensi P, Grimaldi A, Piquemal R, Touraine P, Trembath RC, Capeau J: Lamin A/C gene: sexdetermined expression of mutations in Dunnigan-type familial partial lipodystrophy and absence of coding mutations in congenital and acquired generalized lipoatrophy. Diabetes 2000, 49:1958-1962

22. Vantyghem MC, Pigny P, Maurage CA, Rouaix-Emery N, Stojkovic T, Cuisset JM, Millaire A, Lascols O, Vermersch P, Wemeau JL, Capeau J, Vigouroux C: Patients with familial partial lipodystrophy of the Dunnigan type due to a LMNA R482W mutation show muscular and cardiac abnormalities. J Clin Endocrinol Metab 2004, 89:5337-5346

23. Jan V, Cervera $P$, Maachi M, Baudrimont M, Kim M, Vidal H, Girard PM, Levan P, Rozenbaum W, Lombès A, Capeau J, Bastard JP Altered fat differentiation and adipocytokine expression are interrelated and linked to morphological changes and insulin resistance in HIV-1-infected lipodystrophic patients. Antivir Ther 2004, 9:555-564

24. Nolan D, Hammond E, Martin A, Taylor L, Herrmann S, McKinnon E, Metcalf C, Latham B, Mallal S: Mitochondrial DNA depletion and morphologic changes in adipocytes associated with nucleoside reverse transcriptase inhibitor therapy. AIDS 2003, 17:1329-1338

25. Kim MJ, Leclercq P, Lanoy E, Cervera P, Antuna-Puente B, Maachi M, Dorofeev E, Slama L, Valantin MA, Costagliola D, Lombès A, Bastard JP, Capeau J: A 6-month interruption of antiretroviral therapy improves adipose tissue function in HIV-infected patients: the ANRS EP29 Lipostop Study. Antivir Ther 2007, 12:1273-1283
26. Meaburn KJ, Cabuy E, Bonne G, Lévy N, Morris GE, Novelli G, Kill IR, Bridger JM: Primary laminopathy fibroblasts display altered genome organization and apoptosis. Aging Cell 2007, 6:139-153

27. Caron M, Auclair M, Sterlingot H, Kornprobst M, Capeau J: Some HIV protease inhibitors alter lamin A/C maturation and stability. SREBP-1 nuclear localization and adipocyte differentiation. AIDS 2003, 17:2437-2344

28. Guallar JP, Gallego-Escuredo JM, Domingo JC, Alegre M, Fontdevila J, Martinez E, Hammond EL, Domingo P, Giralt M, Villarroya F: Differential gene expression indicates that "buffalo hump" is a distinct adipose tissue disturbance in HIV-1-associated lipodystrophy. AIDS 2008, 22:575-584

29. Wojtanik KM, Edgemon K, Viswanadha S, Lindsey B, Haluzik M, Chen W, Poy G, Reitman M, Londos C: The role of LMNA in adipose: a novel mouse model of lipodystrophy based on the Dunnigan-type familial partial lipodystrophy mutation. J Lipid Res 2009, 50:1068-1079

30. Holme E, Larsson NG, Oldfors A, Tulinius M, Sahlin P, Stenman G Multiple symmetric lipomas with high levels of mtDNA with the tRNA(Lys) A-> G(8344) mutation as the only manifestation of disease in a carrier of myoclonus epilepsy and ragged-red fibers (MERRF) syndrome. Am J Hum Genet 1993, 52:551-556

31. Fleischmajer R, Nedwich A: Progeria (Hutchinson-Gilford). Arch Dermatol 1973, 107:253-258

32. Erdem N, Gunes AT, Avci O, Osma E: A case of Hutchinson-Gilford progeria syndrome mimicking scleredema in early infancy. Dermatology 1994, 188:318-321

33. Nguyen D, Leistritz DF, Turner L, MacGregor D, Ohson K, Dancey P, Martin GM, Oshima J: Collagen expression in fibroblasts with a nove LMNA mutation. Biochem Biophys Res Commun 2007, 352:603-608

34. Henegar C, Tordjman J, Achard V, Lacasa D, Cremer I, Guerre-Millo M, Poitou C, Basdevant A, Stich V, Viguerie N, Langin D, Bedossa P Zucker JD, Clément K: Adipose tissue transcriptomic signature highlights the pathological relevance of extracellular matrix in human obesity. Genome Biol 2008, 9:R14

35. Cancello R, Clément K: Is obesity an inflammatory illness? role of low-grade inflammation and macrophage infiltration in human white adipose tissue. BJOG 2006, 113:1141-1147

36. Halberg N, Khan T, Trujillo ME, Wernstedt-Asterholm I, Attie AD, Sherwan S, Wang ZV, Landskroner-Eiger S, Dineen S, Magalang UJ, Brekken RA, Scherer PE: Hypoxia-inducible factor 1alpha induces fibrosis and insulin resistance in white adipose tissue. Mol Cell Biol 2009, 29:4467-4483

37. Sevastianova K, Sutinen J, Greco D, Sievers M, Salmenkivi K, Perttila J, Olkkonen VM, Wagsater D, Lidell ME, Enerback S, Eriksson P Walker UA, Auvinen P, Ristola M, Yki-Jarvinen H: Comparison of dorsocervical with abdominal subcutaneous adipose tissue in patients with and without antiretroviral therapy-associated lipodystrophy. Diabetes 2011, 60:1894-1900

38. Frontini A, Cinti S: Distribution and development of brown adipocytes in the murine and human adipose organ. Cell Metab 2010, 11:253-256

39. Rodriguez de la Concepcion ML, Domingo JC, Domingo P, Giralt M, Villarroya F: Uncoupling protein 1 gene expression implicates brown adipocytes in highly active antiretroviral therapy-associated lipomatosis. AIDS 2004, 18:959-960

40. Langin D: Recruitment of brown fat and conversion of white into brown adipocytes: strategies to fight the metabolic complications of obesity? Biochim Biophys Acta 2010, 1801:372-376

41. Xue B, Rim JS, Hogan JC, Coulter AA, Koza RA, Kozak LP: Genetic variability affects the development of brown adipocytes in white fat but not in interscapular brown fat. J Lipid Res 2007, 48: 41-51

42. Barbatelli G, Murano I, Madsen L, Hao Q, Jimenez M, Kristiansen K, Giacobino JP, De Matteis R, Cinti S: The emergence of coldinduced brown adipocytes in mouse white fat depots is predominantly determined by white to brown adipocyte transdifferentiation. Am J Physiol Endocrinol Metab 2010, 298:E1244-E1253 